\title{
Stochastic Modeling of Particle Deposition in Lungs of Cystic Fibrosis Patients
}

\author{
Robert Sturm \\ Division of Physics and Biophysics, Department of Material Sciences and Physics, University of Salzburg Hellbrunner Str. 34, \\ A-5020 Salzburg, Austria \\ Correspondence should be addressed to Robert Sturm, sturm_rob@hotmail.com
}

Received 2 March 2011; Accepted 7 April 2011

Academic Editors: A. P. Comellas and A. Mohan

Copyright ( $) 2011$ Robert Sturm. This is an open access article distributed under the Creative Commons Attribution License, which permits unrestricted use, distribution, and reproduction in any medium, provided the original work is properly cited.

A stochastic model describing particle deposition in cystic fibrosis (CF) patients has been developed. The model should help to optimize drug administration in the treatment of CF by exploring those physiologic and physical parameters that are responsible for the delivering of pharmaceutical aerosols to appropriate sites (receptor cells). Concerning the modeling of deposition, changes of the lungs due to CF were expressed by either constant or random scaling of the airway calibers. Additionally, continuous enlargement of the alveoli and the definition of asymmetric breathing cycles (different lengths for inhalation and exhalation time) were carried out. Application of these model considerations to three different age groups (infants, children, and adults) showed that permanent reduction of the airway calibers generally increases deposition in the tracheobronchial tree by more than $100 \%$ with respect to healthy controls. The fraction of particles deposited in the alveoli and alveolar ducts may be decreased at the same time. These tendencies are even more pronounced by the simulation of emphysema and by extending exhalation time with respect to inhalation time. Relative particle fractions deposited in the tracheobronchial compartment significantly increase from infant to adult.

\section{Introduction}

Cystic fibrosis (CF) is regarded as the most common, lifeshortening, recessive genetic disorder among Caucasians [13]. As a complicating factor of this disease, the age of diagnosis and severity of symptoms are subject to a significant interindividual variability. In general, CF involves exocrine gland dysfunction and, therefore, affects multiple organ systems in the human body, including the lungs, digestive tract, reproductive organs, sweat glands, and, finally, the skeletal framework [4]. Most severe burdens, however, can be recognized for the digestive and respiratory system, where $\mathrm{CF}$ is characterized by chronic obstruction and infection of the airways as well as an insufficiency of the pancreas in providing digestive enzymes. Ultimately, numerous people suffering from CF die due to a heart failure which is caused by the respiratory consequences of this disease [4].

Regarding the impairment of the respiratory system, CF affects both the lower respiratory tract with the trachea and the lungs as well as the upper respiratory tract, including the nose and the sinuses [1-4]. According to several medical studies [5-7], CF mainly produces thick layers of mucus lining the bronchial airways (Figure 1). Due to a defect of the chloride channels in the respective gland cells, this mucus is additionally marked by a continuous dehydration and thus an increasing viscosity. The rheology of the mucus is also influenced by a rising content of DNA fragments and actin filaments released from necrotic granulocytes [4]. The hypersecretion and accumulation of highly viscous mucus obstruct breathing passages and interfere with the removal of deposited bacteria, viruses, and other particulate antigens from the airways. Therefore, individuals with CF often suffer chronic lung infections, followed by inflammation and subsequent lung damage. Such insufficiencies of the bronchial airways include chronic obstructive bronchitis, bronchiectasis of small ciliated airways, and, at later stages of the disease, bronchiolitis, pneumonitis, and regional emphysema with diffuse alveolar destruction (Figure 1) [5].

Techniques for measuring changes of the lung physiology in CF patients have been considerably improved during the past decades and comprise the analysis of breath mechanics (flow volume measurements) as well as parameters for 
lung growth (static lung volumes) and for intrapulmonary gas distribution $[5,8]$. In general, a continuous bronchial obstruction is expressed by an increase of the airway resistance Raw (decrease of the airway conductance Gaw) as well as a growing functional residual capacity FRC which is most significant in the so-called miscellaneous CF type [5]. With further progress of the disease, FRC as a measure of the ventilated lung space is reduced, again, whereas dead lung space is remarkably enhanced. At the final stage of $\mathrm{CF}, \mathrm{paCO}_{2}$ and its permanent increase become important parameters for further prognoses [5].

Optimized deposition of medical aerosols in COPD lungs presupposes an extensive knowledge of particle behaviour in abnormally narrowed airways and remarkably enlarged alveoli. Besides the application of medical techniques (e.g., SPECT), respective data can be also created from reliable computer models considering the specific properties of diseased lungs (airway geometry, lung volumes, breathing behaviour). A model approach of aerosol deposition in CFaffected lungs has been recently carried out by Martonen et al. [9] who described the lungs of patients inflicted with CF by different morphologies and studied affected ventilatory parameters and their effects upon drug deposition. In order to get an idea about the local deposition behaviour, particle distributions were computed on a generation-by-generation basis in this model. Progressive obstruction of single airways was realized by introducing an "airway coefficient", expressing possible changes of the airway caliber. Simulation of particle deposition in COPD lungs has been also outlined by several authors [10-12], partly using the stochastic Monte Carlo deposition model formerly introduced by Koblinger and Hofmann [13]. Besides a constant reduction of the airway caliber, this model also considered a random reduction of respective airway diameters, total airway blockage, and late-stage emphysema. Breathing parameters were adjusted to the changed lung volumes (FRC, tidal volume). Alföldy et al. [14] used the nearly identical model for a reliable simulation of particle deposition in asthma patients and tried to optimize the deposition patterns of inhaled pharmaceuticals by varying particle sizes and breathing parameters. As an advanced feature, the asthma model assumed asymmetric breathing cycles, that is, different times for inhalation and exhalation.

This study intends to expand on previously published works dealing with particle deposition in obstructed and emphysematous lungs, thereby using different approaches to airway obstruction (constant and random scaling of airway calibers). Additionally, asymmetric breathing cycles for CF patients, and slightly different airway scaling (Raw) between inhalation and exhalation are applied.

\section{Methods}

2.1. Simulation of Particle Deposition in CF Lungs. As outlined above, the basic mathematical model for this approach has been developed by Koblinger and Hofmann [13] and has been specifically advanced to fulfil the main requirements regarding particle deposition in COPD lungs.
In the original model, aerosol inhalation and deposition is simulated, using a stochastic morphometry of the human lung. As a significant feature, this stochastic lung model involves experimentally observed branching asymmetries of the tracheobronchial tree and an intrasubject variability of airway calibers and lengths $[18,19]$. Airway geometry is uniformly scaled to a functional residual capacity of $3300 \mathrm{~mL}$ with the respective formulae suggested by the International Commission on Radiological Protection (ICRP) [16].

For simulating aerosol deposition in CF lungs, airway diameters were calibrated according to different scaling scenarios, applying scaling factors that were randomly selected out of a predefined interval (Figure 2(a)). To find a physiologically meaningful order of magnitude for the range of scaling, the extent of airway caliber reduction is based upon the airway resistance, Raw, which represents a physical standard parameter included in most lung function tests. In general airway resistance in a single airway, $\mathrm{Raw}_{i}$, is given by

$$
\operatorname{Raw}_{i}=\frac{\left(8 \cdot l_{i} \cdot \eta\right)}{\pi \cdot r_{i}^{4}} \text { (Poiseuille's Law), }
$$

where $l_{i}$ denotes the airway length in $\mathrm{cm}, r_{i}$ the airway radius in $\mathrm{cm}$, and $\eta$ the viscosity of air at $20^{\circ} \mathrm{C}\left(1.83 \cdot 10^{-4} \mathrm{P}\right)$. The resistance in all airways in generation $k, \mathrm{Raw}_{k}$, is calculated by

$$
\operatorname{Raw}_{k}=\frac{1}{n_{k}} \operatorname{Raw}_{k, \text { mean }} \text { (resistors in parallel), }
$$

with $n_{k}$ denoting the number of airways in generation $k$ and $\mathrm{Raw}_{k \text {,mean }}$ representing the mean airway resistance in generation $k$. The total resistance in the whole tracheobronchial tree, $\mathrm{Raw}_{T B}$, is obtained by summing up the resistance values of all tracheobronchial airway generations [20]:

$$
\operatorname{Raw}_{T B}=\sum_{k=1}^{21} \operatorname{Raw}_{k} \text { (resistors in series). }
$$

In the study presented here, a CF-induced $\mathrm{Raw}_{T B}$ of about $2.0 \mathrm{~cm} \mathrm{H}_{2} \mathrm{Os} \mathrm{L}^{-1}$ for patients with a functional residual capacity of $3300 \mathrm{~mL}$ [16] and a $\operatorname{Raw}_{T B}$ of $0.5-1.0 \mathrm{~cm}$ $\mathrm{H}_{2} \mathrm{Os} \mathrm{L}^{-1}$ for children [21] were used to determine the degree of airway diameter reduction. Scaling procedure was conducted according to the iterative algorithm introduced by Martonen et al. [9]. The following scaling scenarios were applied: (1) scaling of bronchial airway calibers by a constant factor $(\mathrm{D}$ (obstr.) $/ \mathrm{D}=$ constant) and (2) reduction of airway diameters by a randomly generated factor $(\mathrm{D}$ (obstr. $) / \mathrm{D}<>$ constant; Figure 2). For both modeling approaches, the trachea was excluded from any scaling procedure, thereby assuming a constant inner diameter of $1.9 \mathrm{~cm}$ in adults. As shown by current medical studies, the tracheal cross-section may be significantly affected in humans with CF, leading to a reduction of the luminal volume in diseased children [22]. This important fact will be considered in future approaches after availability of sufficient experimental data. Concerning the first model, a progress of the lung disease was expressed by a continuous enhancement of the scaling factor (e.g., the change of the scaling factor from 0.8 to 0.6 documented 


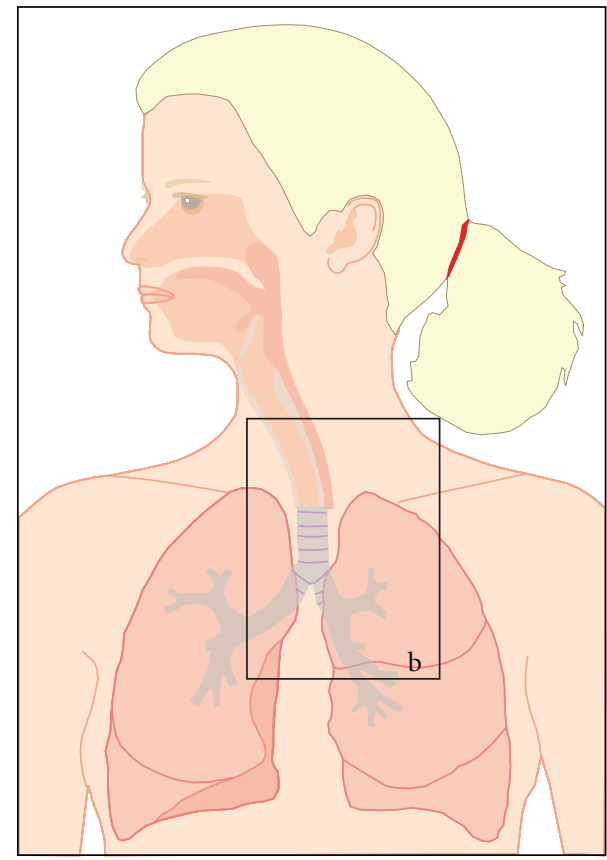

(a)

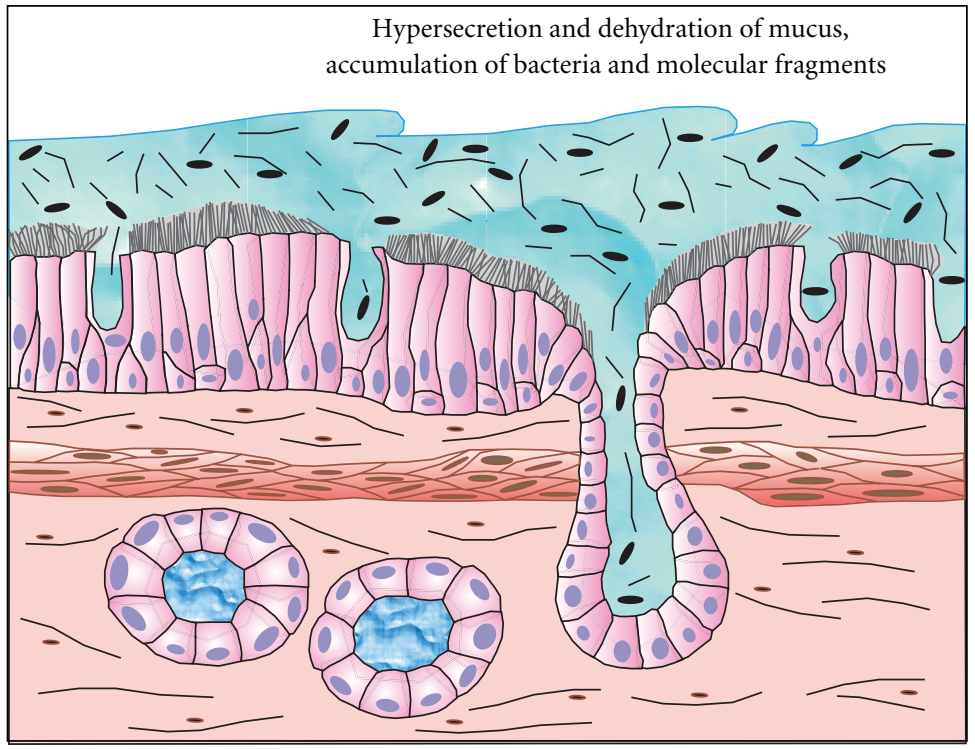

(c)

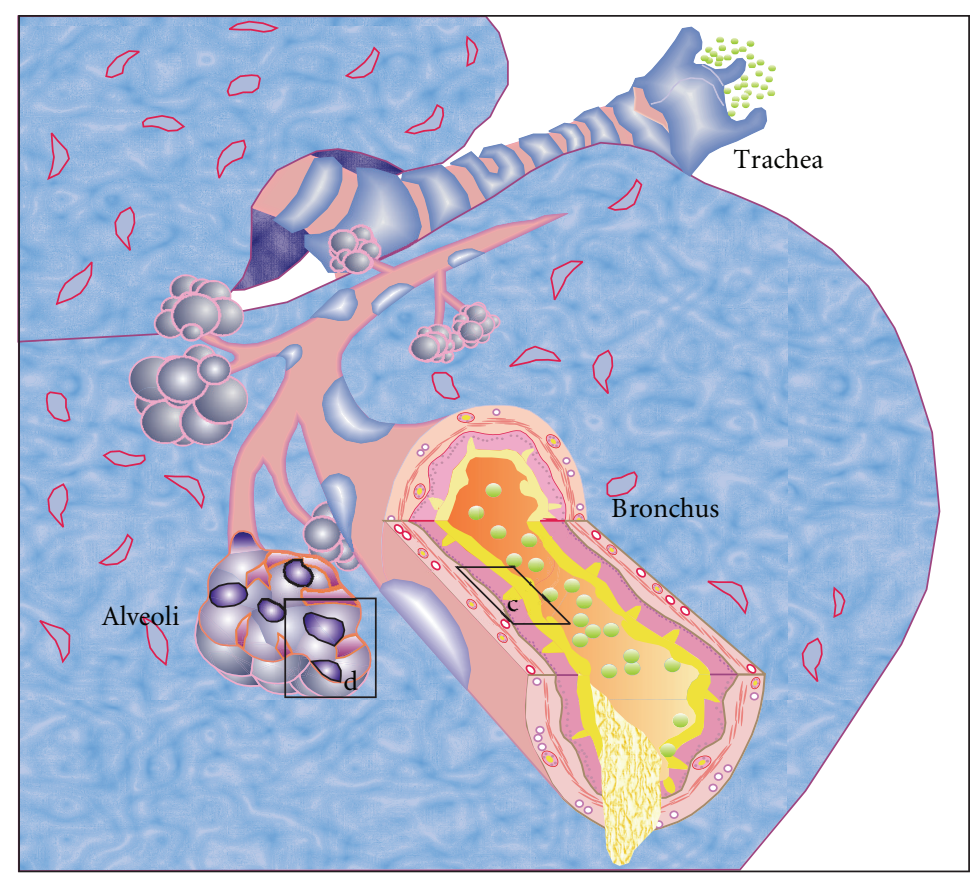

(b)

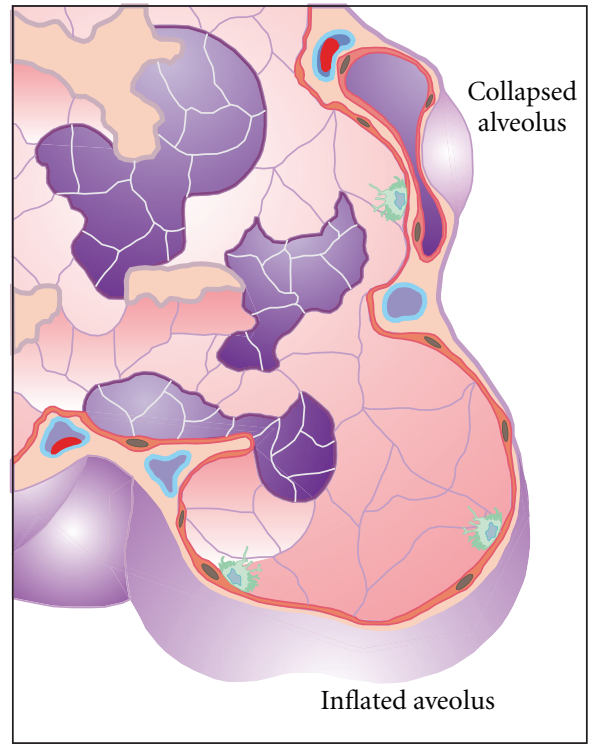

(d)

Figure 1: Schematic presentation of main impairments in the lungs of cystic fibrosis patients. While airways of the tracheobronchial tree are characterized by a hypersecretion of mucus and a possible formation of mucus plugs and clogs as well as a chronic swelling of the airway tissues (b, c), the alveolar region is successively affected by emphysema (d).

a reduction of the airway caliber from 20 to $40 \%)$. By convention, the maximum reduction of airway diameters was determined to $80 \%$, simulating the eventual formation of large-sized mucus plugs. In the second model, the diameter of each airway within a specific path was decreased by a factor that was randomly selected from a predefined range. By setting respective scaling limits to 0.8 and 0.6 , airway calibers were randomly reduced between 20 and 40\%. However, disease progress was simply modeled by shifting this upper limit to higher values, again supposing a maximum diameter reduction of $80 \%$. Independent of the selected model, a possible occurrence of emphysema at later stages of CF was simulated using the respective theoretical approach of Sturm and Hofmann [23], where different types of emphysema and various degrees of emphysematous failure are available.

As outlined in several medical contributions [5, 21, 24], breathing behaviour in COPD patients shows some specificities with respect to the breathing of healthy subjects. 

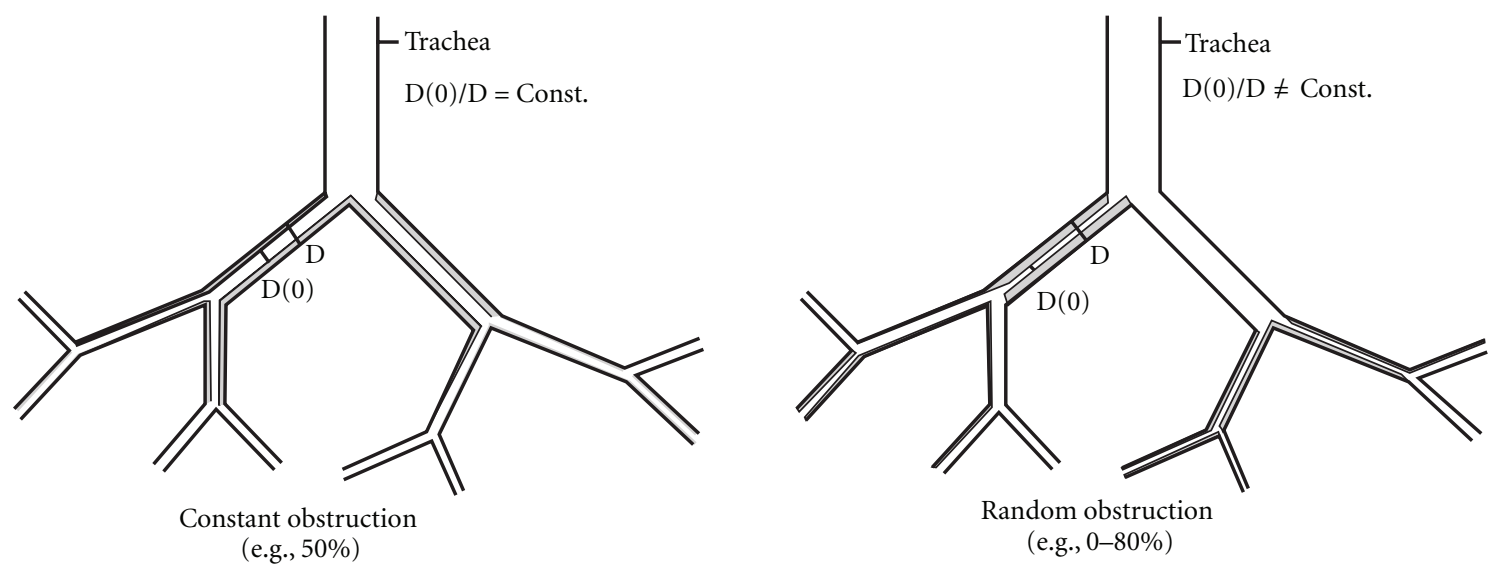

(a)
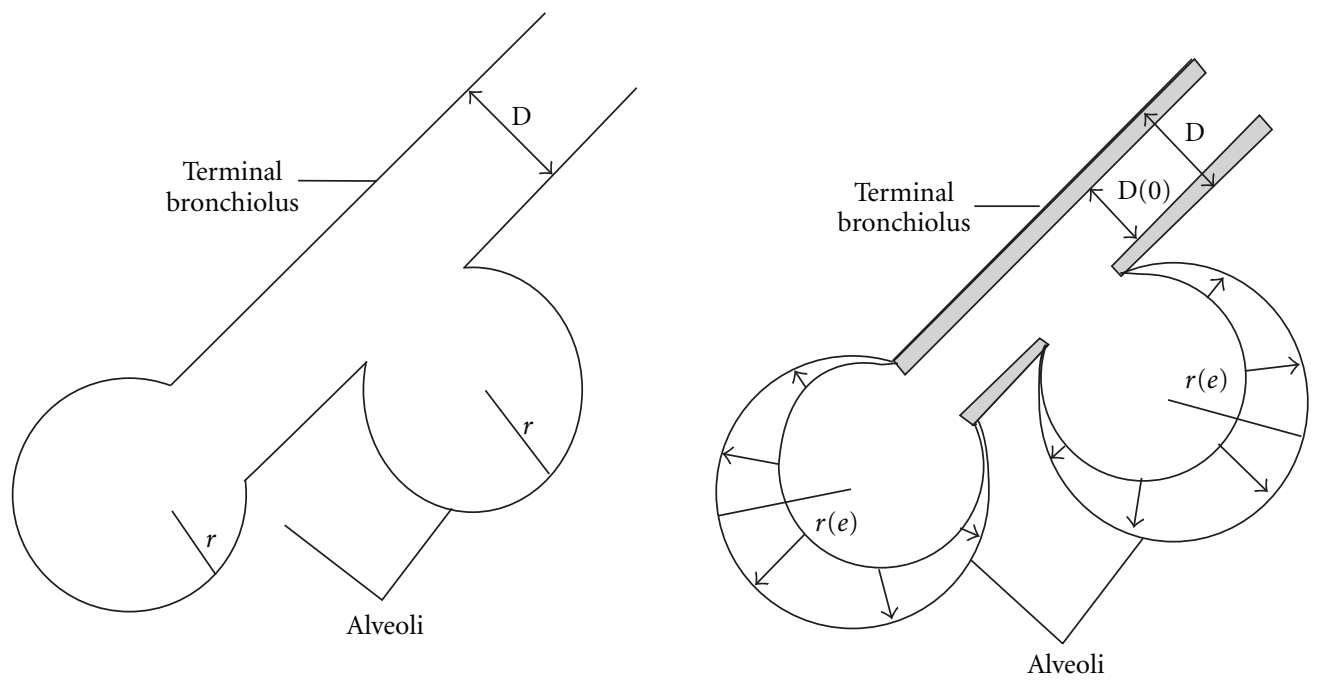

(b)

FIGURE 2: Stochastic modeling of cystic fibrosis: (a) Decrease of the airway calibers due to chronic obstructions is simulated by the application of (1) constant scaling factors $(\mathrm{D}(\mathrm{o}) / \mathrm{D}=$ constant) and (2) random scaling factors $(\mathrm{D}(\mathrm{o}) / \mathrm{D}<>$ constant $)$; (b) Emphysema is modeled by a constant increase of the alveolar radius $(r)$.

Respective irregularities mainly include the development of asymmetric breathing cycles with constant inhalation times, but significantly increased durations for exhalation. Realization of this feature was done by the separate definition of inspiration, expiration, and breath-hold times in the input file of the model program and by regarding its consequences for flow rates and particle deposition. Inhomogeneous ventilation of the lung, a frequently observed feature in COPD patients, was modeled by the introduction of specific parameters providing an asymmetric and asynchronous filling of the lung lobes [25]. At least, decreasing elasticity of the bronchi and bronchioles was approached by a slight variation (about 10\%) of airway scaling between inhalation and exhalation.

\subsection{Selection of Lung Geometries and Breathing Parameters.} Due to its character as a hereditary disease, CF already occurs in infants and adolescents in numerous cases and, therefore, has become one of the most significant children's diseases
[1-3]. While in 1940 most infants born with CF died within the first 2 years of life, in 1998 the median age at death has progressed to 29.8 years. New inhalation therapies promise a further increase of this lifespan. The occurrence of CF among young people is also considered in this contribution by applying the deposition model to three different age groups: (1) 1-year-old infants, (2) 5-year-old children, and (3) adults (25 years). Respective breathing times and volumetric and geometric data (FRC, tidal volume, scaling factors) for healthy subjects of these age groups are summarized in Table 1. Documentation of the disease progress was done by changing the FRCs and breathing frequencies (oral inhalation) and creating asymmetric breathing cycles. For all simulations, monodisperse uniform-density particles with a size of $3 \mu \mathrm{m}$, representing a typical diameter of therapeutic aerosols, were used. Deposition data obtained from the modeling computations were expressed in terms of total deposition (i.e., number of inhaled aerosol particles minus number of exhaled aerosol particles), regional deposition, 


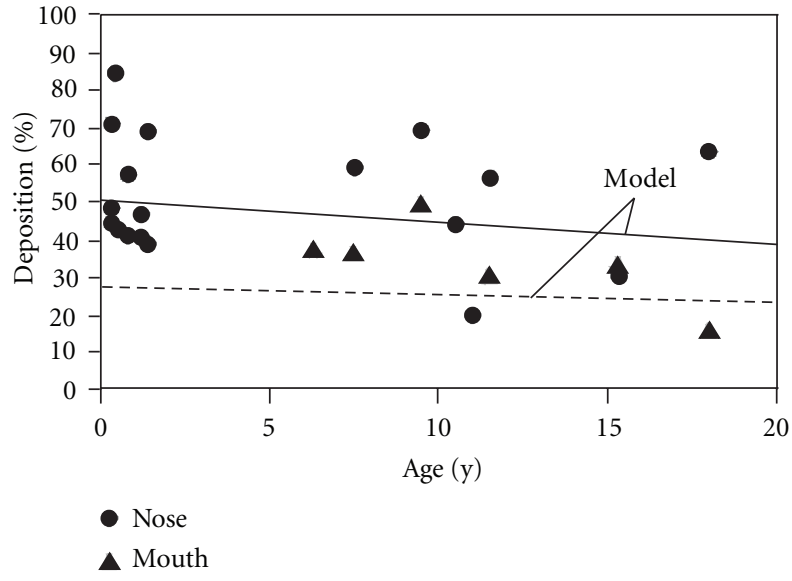

(a)

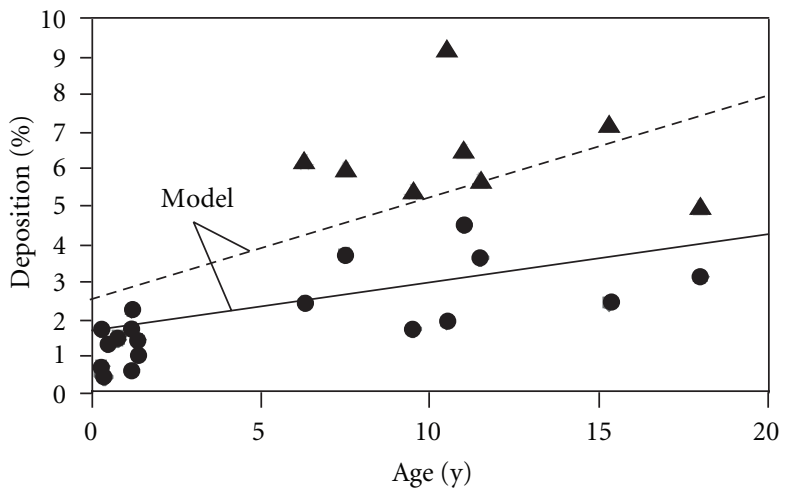

- Nose

$\Delta$ Mouth

(b)

FIgURE 3: Validation of the CF deposition model using experimental data of particle deposition in lungs of CF patients with different age [15]: (a) Extrathoracic deposition (solid line: modeling approach to nose deposition; dashed line: modeling approach to oral deposition), (b) Thoracic deposition after inhalation through the nose or mouth (solid line: modeling approach to nose deposition; dashed line: modeling approach to oral deposition).

TABLE 1: Morphometric scaling factors (SF), breathing conditions, and tracheal mucus velocities (TMV) in the investigated age groups. Breathing data have been taken from the ICRP report vol. 66 [16] while tracheal mucus velocities have been calculated according to the allometric function proposed by Mauderly and Hahn [17]. Abbreviations: FRC: functional residual capacity, TV: tidal volume, BF: breathing frequency, T: length of 1 breath cycle.

\begin{tabular}{lcccccc}
\hline & SF & FRC $(\mathrm{mL})$ & TV $(\mathrm{mL})$ & $\mathrm{BF}\left(\mathrm{min}^{-1}\right)$ & $\mathrm{T}(\mathrm{s})$ & $\mathrm{TMV}\left(\mathrm{mm} \mathrm{min}{ }^{-1}\right)$ \\
\hline 1 year & 0.353 & 244 & 102 & 43.2 & 1.39 & 1.2 \\
5 years & 0.517 & 767 & 213 & 30.0 & 2.00 & 2.7 \\
Adult & 0.840 & 3,300 & 750 & 14.4 & 4.17 & 5.5 \\
\hline
\end{tabular}

thereby distinguishing between extrathoracic, bronchial, and alveolar deposition (Table 2), and generation-by-generation deposition (Figures 4-6).

\section{Results}

3.1. Model Validation. The deposition model presented in this work was validated by using experimental deposition data of CF patients with different age $[15,26]$. The aerosol administered to the older children contained radiolabelled normal saline particles with a mass median aerodynamic diameter (MMAD) of $2.3 \mu \mathrm{m}$ and a related geometric standard deviation (GSD) of 2.3. Infants, on the other hand, inhaled an aerosol including the same type of particles with an MMAD of $3.0 \mu \mathrm{m}$ and a GSD of 2.1. Generally, inhalation was conducted in supine position, whereby production of the aerosol succeeded with a nebulizer that was driven by compressed air at $9 \mathrm{~L} \mathrm{~min}^{-1}$. Whilst infants exclusively breathed through the nose, for older children inhalation through the nasal airways as well as inhalation through the oral airways was studied experimentally. Besides total (i.e., extrathoracic and thoracic) particle deposition, expressed as percentage of the nebulizer output, also regional deposition was measured using planar gamma scans of the children's lungs. Results of the experimental investigation are summa- rized in Figure 3 and plotted together with respective outputs generated by the computer model introduced above. For an appropriate simulation of the experimental data MMADs of the polydisperse aerosols had to be converted to mean aerodynamic diameters. Volumetric lung parameters and breathing characteristics of each CF patient were estimated by using the scaling factors provided by the ICRP [16] (see above). As proposed by the graphs of Figure 3 extrathoracic as well as thoracic particle deposition resulting either from nasal or from oral inhalation are partly well simulated by the theoretical computations, but due to high intersubject variabilities arising among children of the same age, highly reliable predictions are also dramatically complicated. According to the model, extrathoracic particle deposition, no matter if oral or nasal breathing is assumed, continuously decreases with proceeding age whereas particle deposition in the lungs is subject to an increase (Figure 3 ).

3.2. Model Predictions of Particle Deposition in CF Lungs. For all studied age groups, different modeling scenarios have been developed. Besides the calculation of particle fractions deposited in various lung regions (i.e., bronchial, acinar, alveolar), also generation-by-generation plots have been created from representative results. Model data are summarized in Table 2 and partially depicted in Figures 4-6. Concerning 


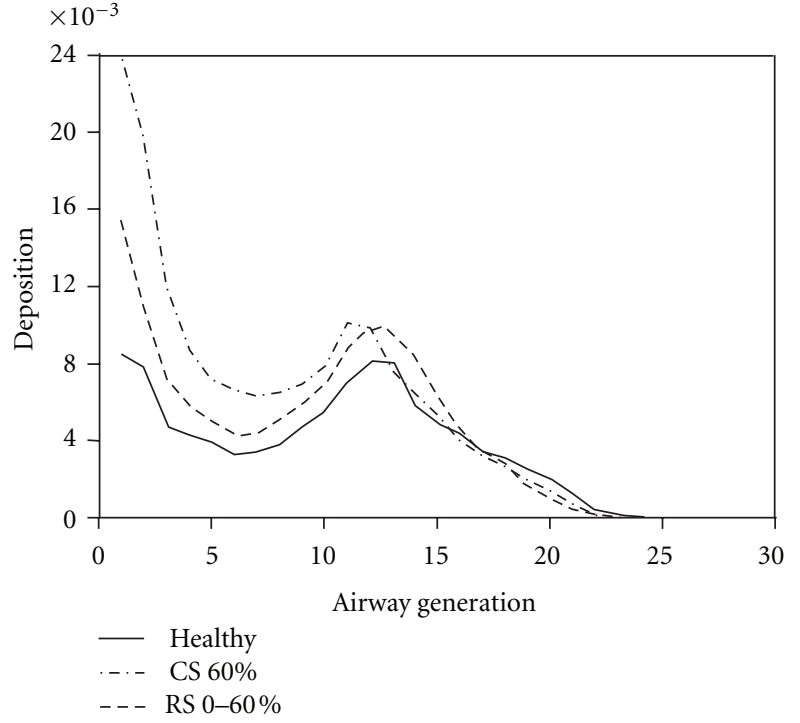

(a)

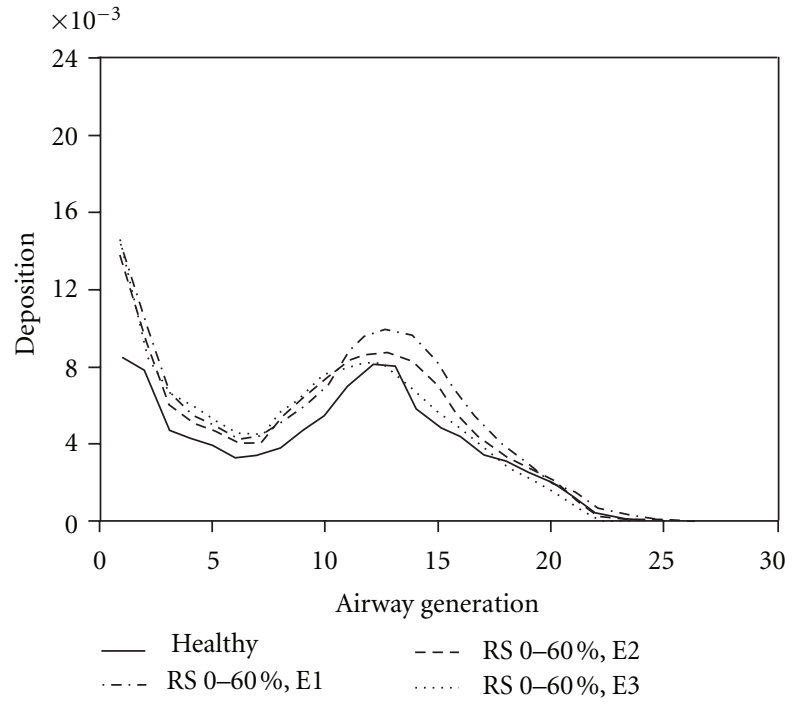

(b)

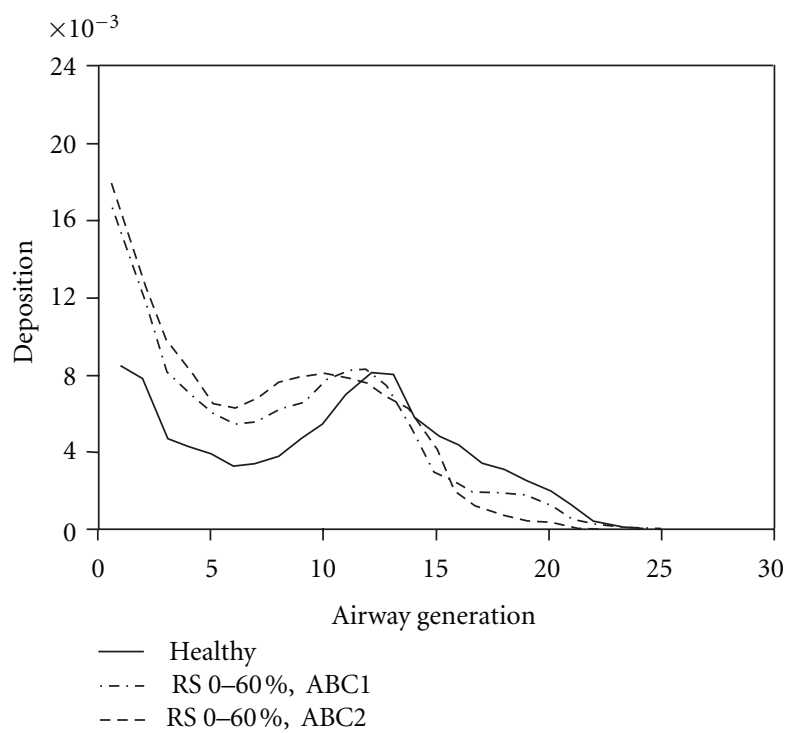

(c)

FIGURE 4: Results of generation-by-generation deposition computation for 1-year-old infants: (a) Deposition patterns in healthy subjects and after assuming constant airway scaling (CS) of 60\% and random airway scaling (RS) ranging from 0 to $60 \%$; (b) Deposition patterns resulting from random scaling $(0-60 \%)$ and emphysema with increasing severity $(\mathrm{E} 1=500 \mu \mathrm{m}$ alveolar diameter, E2 $=750 \mu \mathrm{m}$ alveolar diameter, E3 = $1 \mathrm{~mm}$ alveolar diameter); (c) Deposition patterns resulting from random scaling (0-60\%) and asymmetric breathing cycles $(\mathrm{ABC} 1: \mathrm{ET}=1.5 \mathrm{IT}, \mathrm{ABC} 2 \mathrm{ET}=2 \mathrm{IT})$.

aerosol particle deposition in infants, changes of the airway calibers due to constant or random scaling cause a significant increase of total deposition (Table 2) with rapidly increasing fractions of bronchial deposition, but only slightly decreasing amounts of particles deposited in the alveolar region. Extrathoracic deposition can be regarded as nearly constant for all model scenarios, ranging from 0.9 to $1.3 \%$. As proposed in Figure 4(a), bronchial deposition is more significantly affected by constant scaling of the airways than by random scaling, the latter of which represents the more realistic case in lungs of CF patients. Consideration of emphysema appearing at later stages of CF (i.e., increase of the alveolar diameter $\mathrm{AD}$ ) causes the opposite effect with decreasing total deposition (Table 2) due to a remarkable loss of particles settling down in the alveoli (Figure 4(b)). The application of asymmetric breathing cycles additionally enhances total particle deposition in the lung (Table 2), but, contrary to simple airway scaling, aerosol fractions deposited in the ductal and alveolar parts of the lung are increased in a similar fashion (Figure 4(c)). For 5-year-old children, application of diverse modeling scenarios results in identical effects on pulmonary particle deposition as for infants. Main differences between the two age groups may be recognized regarding the relative amounts of deposited particle fractions (Table 2). 
TABLE 2: Results of deposition modeling in healthy subjects and CF patients. Besides constant and random obstruction of the airways, lung disease has been additionally simulated by a continuous enlargement of the alveoli (AD: alveolar diameter), and the creation of asymmetric breathing cycles (IT: inhalation time, ET: exhalation time). * Random scaling assuming a maximum decrease of the airway calibers of $60 \%$ (note: results are shown for one stochastically generated lung).

\begin{tabular}{|c|c|c|c|c|c|c|}
\hline \multicolumn{7}{|c|}{ Infant ( 1 year $)$} \\
\hline & \multirow[t]{2}{*}{ Healthy } & \multicolumn{2}{|c|}{ Constant scaling } & \multicolumn{3}{|c|}{ Random scaling } \\
\hline & & $40 \%$ & $60 \%$ & $0-20 \%$ & $0-40 \%$ & $0-60 \%$ \\
\hline Extrathoracic & $0.91 \%$ & $0.92 \%$ & $0.85 \%$ & $1.12 \%$ & $1.14 \%$ & $1.05 \%$ \\
\hline Bronchial & $10.20 \%$ & $17.00 \%$ & $19.70 \%$ & $12.70 \%$ & $15.20 \%$ & $17.70 \%$ \\
\hline Alveolar & $0.42 \%$ & $0.31 \%$ & $0.26 \%$ & $0.40 \%$ & $0.32 \%$ & $0.29 \%$ \\
\hline \multirow[t]{3}{*}{ Total } & $11.53 \%$ & $18.23 \%$ & $20.81 \%$ & $14.22 \%$ & $16.66 \%$ & $19.04 \%$ \\
\hline & \multicolumn{3}{|c|}{ Rand. scal.* \& emphysema } & \multicolumn{2}{|c|}{ Rand. scal.* \& asym. b.c. } & \\
\hline & $\mathrm{AD}=500 \mu \mathrm{m}$ & $\mathrm{AD}=750 \mu \mathrm{m}$ & $\mathrm{AD}=1 \mathrm{~mm}$ & $\mathrm{ET}=1.5 \mathrm{IT}$ & $\mathrm{ET}=2.0 \mathrm{IT}$ & \\
\hline Extrathoracic & $1.34 \%$ & $1.23 \%$ & $1.32 \%$ & $0.91 \%$ & $0.93 \%$ & \\
\hline Bronchial & $11.61 \%$ & $10.53 \%$ & $9.23 \%$ & $12.10 \%$ & $11.40 \%$ & \\
\hline Alveolar & $0.35 \%$ & $0.27 \%$ & $0.13 \%$ & $0.53 \%$ & $0.45 \%$ & \\
\hline Total & $13.30 \%$ & $12.03 \%$ & $10.68 \%$ & $13.54 \%$ & $12.78 \%$ & \\
\hline \multicolumn{7}{|c|}{ Child (5 years) } \\
\hline & \multirow[t]{2}{*}{ Healthy } & \multicolumn{2}{|c|}{ Constant scaling } & \multicolumn{3}{|c|}{ Random scaling } \\
\hline & & $40 \%$ & $60 \%$ & $0-20 \%$ & $0-40 \%$ & $0-60 \%$ \\
\hline Extrathoracic & $1.49 \%$ & $1.45 \%$ & $1.34 \%$ & $1.48 \%$ & $1.52 \%$ & $1.42 \%$ \\
\hline Bronchial & $17.90 \%$ & $31.80 \%$ & $38.10 \%$ & $19.10 \%$ & $28.70 \%$ & $34.60 \%$ \\
\hline Alveolar & $2.71 \%$ & $3.06 \%$ & $2.52 \%$ & $2.85 \%$ & $3.06 \%$ & $2.90 \%$ \\
\hline \multirow[t]{3}{*}{ Total } & $22.10 \%$ & $36.31 \%$ & $41.96 \%$ & $23.43 \%$ & $33.28 \%$ & $38.92 \%$ \\
\hline & \multicolumn{3}{|c|}{ Rand. scal.* \& emphysema } & \multicolumn{2}{|c|}{ Rand. scal.* \& asym. b.c. } & \\
\hline & $\mathrm{AD}=500 \mu \mathrm{m}$ & $\mathrm{AD}=750 \mu \mathrm{m}$ & $\mathrm{AD}=1 \mathrm{~mm}$ & $\mathrm{ET}=1.5 \mathrm{IT}$ & $\mathrm{ET}=2.0 \mathrm{IT}$ & \\
\hline Extrathoracic & $1.49 \%$ & $1.56 \%$ & $1.67 \%$ & $1.32 \%$ & $1.30 \%$ & \\
\hline Bronchial & $19.00 \%$ & $17.80 \%$ & $16.51 \%$ & $24.00 \%$ & $22.30 \%$ & \\
\hline Alveolar & $2.40 \%$ & $1.30 \%$ & $0.69 \%$ & $3.60 \%$ & $3.30 \%$ & \\
\hline \multirow[t]{4}{*}{ Total } & $22.99 \%$ & $20.66 \%$ & $18.87 \%$ & $28.92 \%$ & $27.90 \%$ & \\
\hline & \multicolumn{5}{|c|}{ Adult } & \\
\hline & \multirow[t]{2}{*}{ Healthy } & \multicolumn{2}{|c|}{ Constant scaling } & \multicolumn{3}{|c|}{ Random scaling } \\
\hline & & $40 \%$ & $60 \%$ & $0-20 \%$ & $0-40 \%$ & $0-60 \%$ \\
\hline Extrathoracic & $3.20 \%$ & $3.18 \%$ & $3.15 \%$ & $3.20 \%$ & $3.18 \%$ & $3.18 \%$ \\
\hline Bronchial & $26.10 \%$ & $33.80 \%$ & $43.30 \%$ & $27.40 \%$ & $31.90 \%$ & $41.20 \%$ \\
\hline Alveolar & $11.00 \%$ & $13.90 \%$ & $14.40 \%$ & $11.60 \%$ & $12.40 \%$ & $13.50 \%$ \\
\hline \multirow[t]{3}{*}{ Total } & $40.30 \%$ & $50.88 \%$ & $60.85 \%$ & $42.20 \%$ & $47.48 \%$ & $57.88 \%$ \\
\hline & \multicolumn{3}{|c|}{ Rand. scal.* \& emphysema } & \multicolumn{2}{|c|}{ Rand. scal.* \& asym. b.c. } & \\
\hline & $\mathrm{AD}=500 \mu \mathrm{m}$ & $\mathrm{AD}=750 \mu \mathrm{m}$ & $\mathrm{AD}=1 \mathrm{~mm}$ & $\mathrm{ET}=1.5 \mathrm{IT}$ & $\mathrm{ET}=2.0 \mathrm{IT}$ & \\
\hline Extrathoracic & $3.21 \%$ & $3.20 \%$ & $3.23 \%$ & $3.18 \%$ & $3.20 \%$ & \\
\hline Bronchial & $32.10 \%$ & $31.50 \%$ & $30.90 \%$ & $36.50 \%$ & $35.80 \%$ & \\
\hline Alveolar & $7.50 \%$ & $6.30 \%$ & $4.90 \%$ & $12.50 \%$ & $12.10 \%$ & \\
\hline Total & $42.81 \%$ & $41.00 \%$ & $39.03 \%$ & $52.18 \%$ & $51.10 \%$ & \\
\hline
\end{tabular}

Due to increased dimensions of the airway calibers and lengths in children with respect to infants, higher amounts of aerosol particles are deposited in the alveoli and the bronchial airways (Figure 5). A further progress of this phenomenon can be observed for adults, whose lungs are about 2.5-times as big as those of 1-year-old infants and about 1.7-times as big as the lungs of 5-year-old children. As depicted in Table 2, discrepancies of bronchial and acinar (alveolar) deposition fractions of adults exceed those of infants by a factor of 2.53.0, depending on the respective model scenario. Increased alveolar and bronchial deposition in fully developed lungs is also reflected in the graphs of Figure 6. 


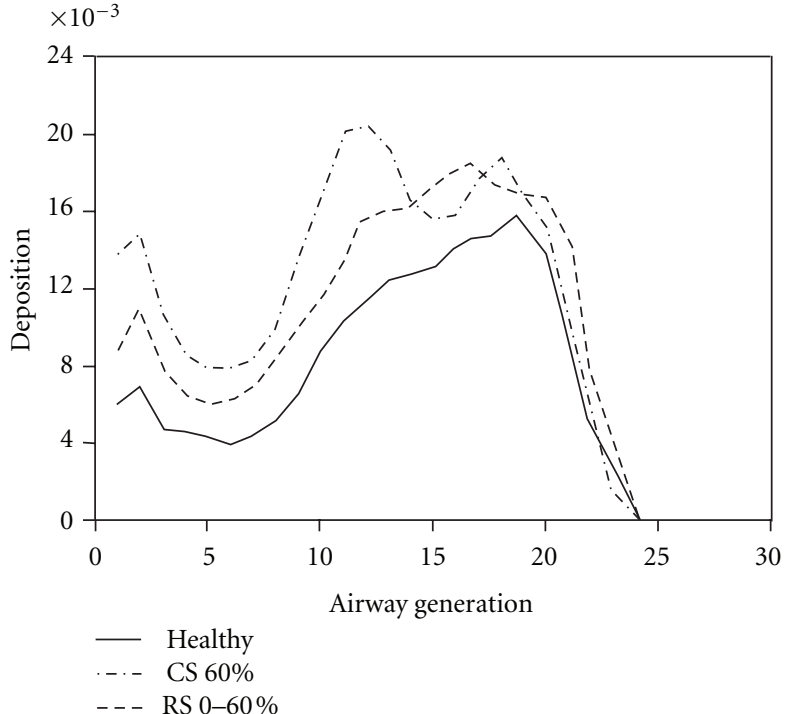

(a)

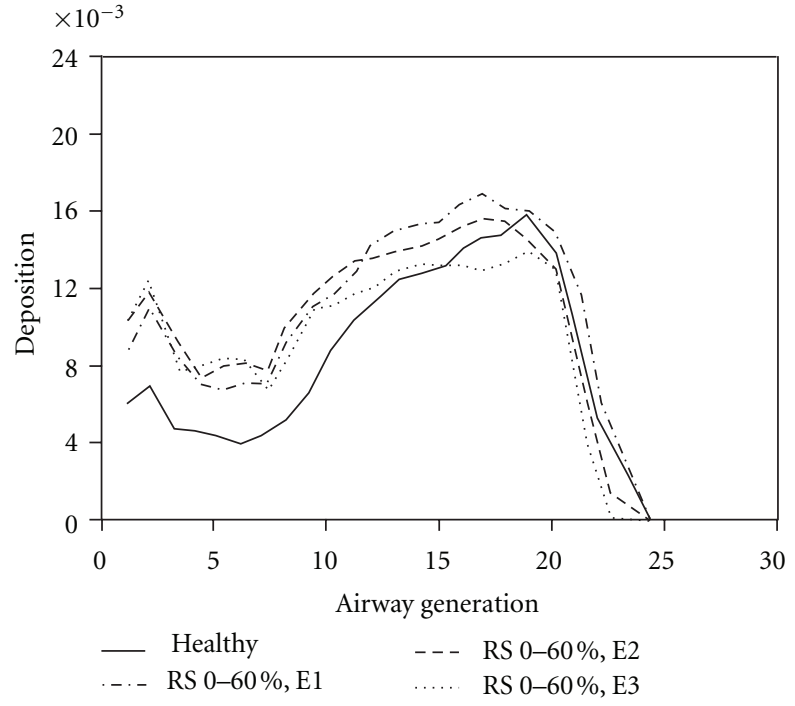

(b)

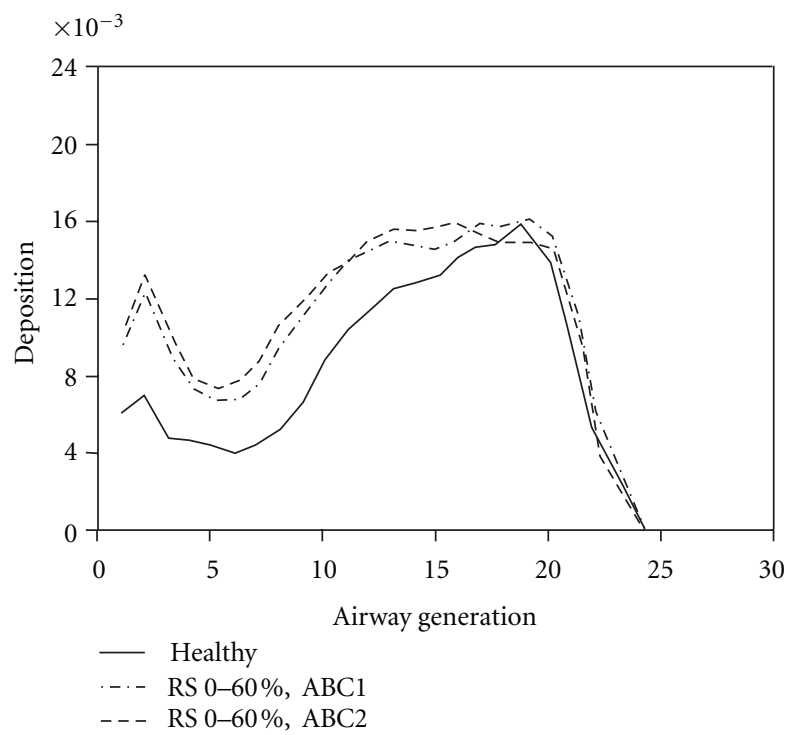

(c)

FIGURE 5: Results of generation-by-generation deposition computation for 5-year-old children; for detailed explanations of the abbreviations see Figure 4.

\section{Discussion}

Cystic fibrosis is a complex multisystem disease with relatively high incidence rate (about 1 in 2,500 births) and thus with the demand for increased awareness among medical and life scientists. Regarding CF-induced impairments of the lungs, the recent development of specific physical and medical therapies including the inhalation of aerosolized drugs has markedly improved quality of life of young and adult patients. However, the development of inhalation techniques is still subject to a rapid progress, focussing on the enhancement of aerosol efficacies due to drug distribution to appropriate sites within the tracheobronchial tree. In this situation, the optimum employment of mathematical models can assist the physician in targeting the delivery of inhaled pharmaceuticals. With the help of such models, various physiological and physical parameters influencing aerosol deposition can be tested, and, hence, time-consuming and expensive experiments can be substituted to a certain degree.

In the present contribution, a mathematical model for the deposition of particles in the lungs of CF patients was developed and subsequently applied to various age groups (infants, children, adults), breathing conditions, and particle sizes. As a main innovation compared to previous models, the recent approach is based on a stochastic lung morphometry with respective variabilities of the airway dimensions within each lung generation $[13,18,19,27]$. 


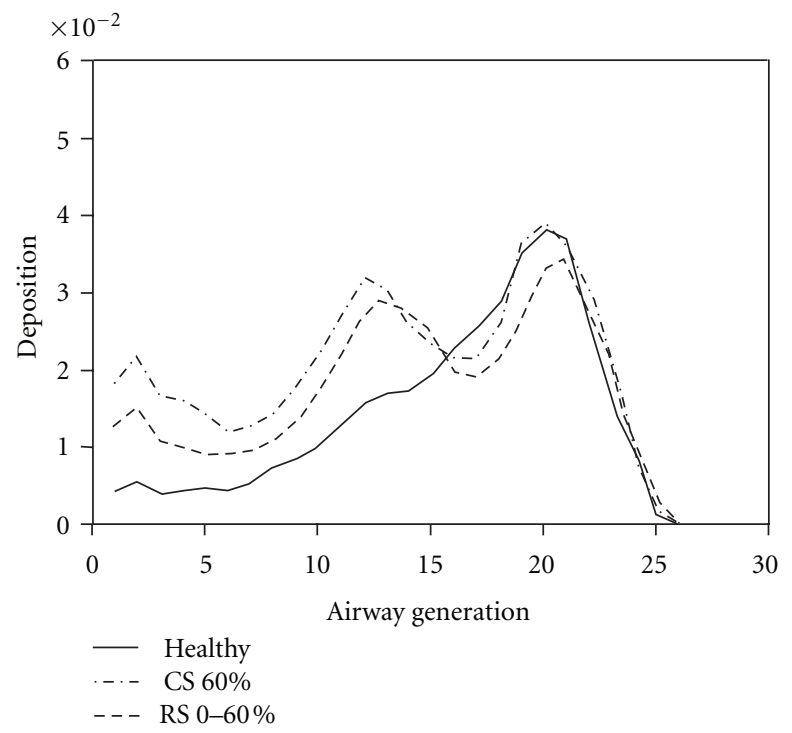

(a)

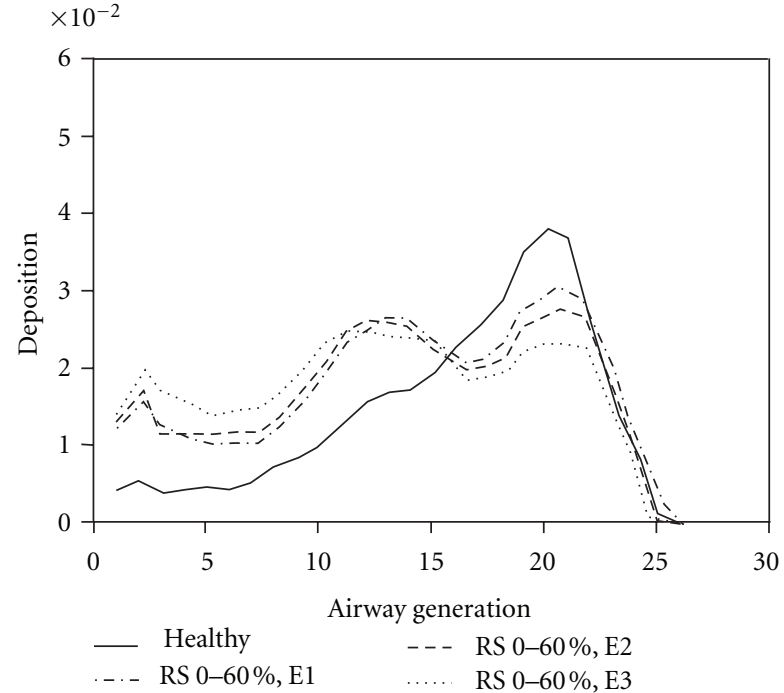

(b)

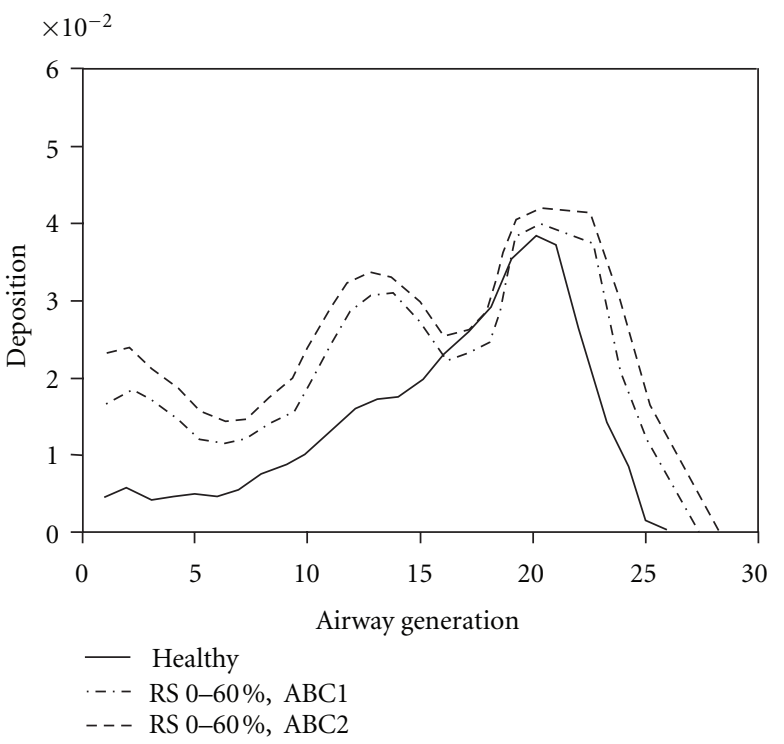

(c)

FIGURE 6: Results of generation-by-generation deposition computation for adults; for detailed explanations of the abbreviations see Figure 4.

Concerning the deposition model, main interest focussed on the question of whether the sites of deposited aerosols within the lung differ significantly with morphology, breathing, and particle diameter. To give a reliable answer to this question, CF-affected lungs were simulated as substantially as possible by the constant or random change of airway calibers and the continuous enlargement of single alveoli. Possible changes in the breathing behaviour of CF patients were considered by the definition of asymmetric breathing cycles, where inhalation and exhalation times are characterized by different lengths. In accordance with previous studies on other lung diseases (e.g., asthma, COPD [28-30]), exhalation time was increased by a factor of 1.5 to 2.0 , while inhalation time was kept on a constant level. As outlined in standard publications of CF [1-3], the disease is mainly located in the bronchi and associated small ciliated airways, where abnormal secretion of mucus chiefly impairs the clearance of deposited particles and, therefore, increases the risk of infection and related inflammation. As suggested by numerous computer simulations, efficiency of drug deposition within these specific parts of the lung can be controlled to a high extend by the selection of a monodisperse aerosol with appropriate particle diameter. Respective deposition efficiencies were calculated from a simple mathematical function for aerosol sizes ranging from 1 to $20 \mu \mathrm{m}$.

As could be demonstrated by the variation of different model parameters, particle deposition in the tracheobronchial and the alveolar regions behaves in a very systematic manner (Table 2, Figures 4-6). For all age groups, constant reduction of the airway calibers, signifying that 
these airways have become congested, causes increased deposition in the bronchi and bronchioli whereas deposition in the alveoli is decreased due to a lower probability of aerosols penetrating to these sites. For random scaling of the airway calibers, similar but less significant tendencies of deposition can be observed. The development of emphysema additionally intensifies particle deposition in the ciliated airways and depletion of deposited aerosols in the gas-exchanging part of the lung, whilst application of asymmetric breathing cycles leads to a general increase of particle deposition again. As outlined by Martonen et al. $[9,31]$, inertial impaction can be identified as the main deposition mechanism of $\mu \mathrm{m}$-sized particles and depends on various geometric parameters and particle (air) velocity. The magnitude of particle (air) velocity is determined by the inspiratory flow rate, the cross-section of an airway tube, and the extend of flow splitting within one lung generation (i.e., the number of airways). Therefore, with decreasing airway diameter, particle velocity and effectiveness of impaction become enhanced. In infants, this phenomenon is less pronounced due to the relatively short breathing cycles and small inhalative air volumes $[15,16,26]$ (1.4s), producing low inspiratory air flows. In the peripheral airways, inertial impaction is successively substituted by gravitational deposition forces (i.e., sedimentation), whose predominance grows, contrary to impaction, with decreasing particle velocity [16]. However, regarding $3 \mu \mathrm{m}$ particles, deposition in the desired (i.e., in the bronchial) lung region is increased by about $100 \%$ in high-degree CF patients (60\% airway obstruction) with respect to healthy subjects. Optimum particle sizes for highest deposition efficiencies in the tracheobronchial region differ among the age groups due to the respective morphometric and physiological discrepancies, but can be determined within the diameter range from 3 to $7 \mu \mathrm{m}$. As outlined in previous deposition studies [13, 16, 27], larger particles are mainly filtered in the extrathoracic region (oro- or nasopharynx). On the other hand, smaller particles are either characterized by enhanced alveolar deposition or by a generally decreased total deposition due to the lack of effective deposition forces. According to the results presented above, those aerosolized drugs for CF patients, which are thought to enter the circulatory system for eliciting their therapeutical effects (e.g., bronchodilators), should be characterized by submicron size. Deposition of such particles is chiefly controlled by diffusion which behaves relatively insensitive to possible airway obstructions [16]. The results of deposition modeling correspond very well with the previously published model data of Martonen et al. [9] who studied the behaviour of inhaled particles in CFaffected lungs for sedentary and light activity breathing conditions. Eventual discrepancies between both models can be explained by the use of different morphometric data sets (Lovelace data [18] versus Weibel data [32]) as well as slight variations in approaching lung impairments (e.g., consideration of variable obstructions, emphysema, and changing breathing behaviour in the stochastic model). Additionally, breathing conditions for Martonen's calculations were not selected according to the suggestions of the ICRP [16], but from own physiological data [31]. However, the agreement between the results of both models encourages further simulations and model refinements of stochastic deposition in CF-impaired lungs.

\section{References}

[1] S. C. FitzSimmons, "The changing epidemiology of cystic fibrosis," Journal of Pediatrics, vol. 122, no. 1, pp. 1-9, 1993.

[2] R. E. Wood, "Treatment of CF lung disease in first two years," Pediatric Pulmonology, vol. 4, no. 1, pp. 68-70, 1988.

[3] J. F. Tomashefski Jr., C. R. Abramowsky, and B. B. Dahms, "The pathology of cystic fibrosis," in Cystic Fibrosis, P. B. Davis, Ed., pp. 435-489, Marcel Dekker, New York, NY, USA, 1993.

[4] D. Reinhardt, M. Götz, R. Krämer, and M. Schöni, Cystische Fibrose, Springer, Berlin, Germany, 2001.

[5] P. B. Davis, "Pathophysiology of the lung disease in cystic fibrosis," in Cystic Fibrosis, P. B. Davis, Ed., pp. 193-218, Marcel Dekker, New York, NY, USA, 1993.

[6] S. V. Turpin and M. R. Knowles, "Treatment of pulmonary disease in patients with cystic fibrosis," in Cystic Fibrosis, P. B. Davis, Ed., pp. 277-344, Marcel Dekker, New York, NY, USA, 1993.

[7] M. W. Konstan and M. Berger, "Infection and inflammation of the lung in cystic fibrosis," in Cystic Fibrosis, P. B. Davis, Ed., pp. 219-276, Marcel Dekker, New York, NY, USA, 1993.

[8] P. J. Anderson, J. D. Blanchard, J. D. Brain, H. A. Feldman, J. J. McNamara, and J. Heyder, "Effect of cystic fibrosis on inhaled aerosol boluses," American Review of Respiratory Disease, vol. 140, no. 5, pp. 1317-1324, 1989.

[9] T. Martonen, I. Katz, and W. Cress, "Aerosol deposition as a function of airway disease: cystic fibrosis," Pharmaceutical Research, vol. 12, no. 1, pp. 96-102, 1995.

[10] R. Winkler-Heil, R. Sturm, and W. Hofmann, "Calculation of therapeutic aerosol deposition in cystic fibrosis patients," Journal of Aerosol Medicine, vol. 14, no. 4, p. 414, 2001.

[11] R. A. Segal, T. B. Martonen, C. S. Kim, and M. Shearer, "Computer simulations of particle deposition in the lungs of chronic obstructive pulmonary disease patients," Inhalation Toxicology, vol. 14, no. 7, pp. 705-720, 2002.

[12] H. Y. Luo, Y. Liu, and X. L. Yang, "Particle deposition in obstructed airways," Journal of Biomechanics, vol. 40, no. 14, pp. 3096-3104, 2007.

[13] L. Koblinger and W. Hofmann, "Monte Carlo modeling of aerosol deposition in human lungs-part I: simulation of particle transport in a stochastic lung structure," Journal of Aerosol Science, vol. 21, no. 5, pp. 661-674, 1990.

[14] B. Alföldy, R. Sturm, I. Balásházy, W. Hofmann, and I. Boros, "Deposition distribution of therapeutic aerosols in healthy and asthmatic human lungs," in Proceedings of the International Aerosol Conference, pp. 1050-1051, Taipei, Taiwan, 2002.

[15] H. L. Chua, G. G. Collis, A. M. Newbury et al., "The influence of age on aerosol deposition in children with cystic fibrosis," European Respiratory Journal, vol. 7, no. 12, pp. 2185-2191, 1994.

[16] International Commission on Radiological Protection (ICRP), Human Respiratory Tract Model for Radiological Protection, ICRP Publication 66. Annals of the ICRP 24, Pergamon Press, Oxford, UK, 1994.

[17] J. L. Mauderly and F. F. Hahn, Advances in Veterinary Science and Comparative Medicine: The Respiratory System, vol. 26, Academic Press, New York, NY, USA, 1982. 
[18] O. G. Raabe, H. C. Yeh, G. M. Schum, and R. F. Phalen, "Tracheobronchial geometry: human, dog, rat, hamster," Tech. Rep. LF-53, Lovelace Foundation, Albuquerque, NM, USA, 1976.

[19] L. Koblinger and W. Hofmann, "Analysis of human lung morphometric data for stochastic aerosol deposition calculations," Physics in Medicine and Biology, vol. 30, no. 6, pp. 541-556, 1985.

[20] M. King, H. K. Chang, and M. E. Weber, "Resistance of mucuslined tubes to steady and oscillatory airflow," Journal of Applied Physiology: Respiratory Environmental and Exercise Physiology, vol. 52, no. 5, pp. 1172-1176, 1982.

[21] L. Morrison, R. Ball, S. P. Conway, and K. G. Brownlee, "Airway resistance measurements in children with cystic fibrosis," Physiotherapy, vol. 89, no. 11, pp. 629-636, 2003.

[22] D. K. Meyerholz, D. A. Stoltz, E. Namati et al., "Loss of cystic fibrosis transmembrane conductance regulator function produces abnormalities in tracheal development in neonatal pigs and young children," American Journal of Respiratory and Critical Care Medicine, vol. 182, no. 10, pp. 1251-1261, 2010.

[23] R. Sturm and W. Hofmann, "Stochastic simulation of alveolar particle deposition in lungs affected by different types of emphysema," Journal of Aerosol Medicine, vol. 17, no. 4, pp. 357-372, 2004.

[24] G. Dockter, H. Lindemann, and B. Tümmler, Mukoviszidose, Thieme, Stuttgart, Germany, 2000.

[25] J. Milic-Emili, J. A. M. Henderson, M. B. Dolovich, D. Trop, and K. Kaneko, "Regional distribution of inspired gas in the lung," Journal of Applied Physiology, vol. 21, no. 3, pp. 749759, 1966.

[26] S. G. Devadason, M. L. Everard, C. MacEarlan et al., "Lung deposition from the Turbuhaler ${ }^{\circledR}$ in children with cystic fibrosis," European Respiratory Journal, vol. 10, no. 9, pp. 20232028, 1997.

[27] W. Hofmann and L. Koblinger, "Monte Carlo modeling of aerosol deposition in human lungs_-part III: comparison with experimental data," Journal of Aerosol Science, vol. 23, no. 1, pp. 51-63, 1992.

[28] A. J. Wardlaw, Asthma, Bios Scientific Publishers, Oxford, UK, 1993.

[29] J. S. Brown, K. L. Zeman, and W. D. Bennett, "Ultrafine particle deposition and clearance in the healthy and obstructed lung," American Journal of Respiratory and Critical Care Medicine, vol. 166, no. 9, pp. 1240-1247, 2002.

[30] J. S. Brown, K. L. Zeman, and W. D. Bennett, "Regional deposition of coarse particles and ventilation distribution in healthy subjects and patients with cystic fibrosis," Journal of Aerosol Medicine, vol. 14, no. 4, pp. 443-454, 2001.

[31] T. B. Martonen, R. C. Graham, and W. Hofmann, "Human subject age and activity level: factors addressed in a biomathematical deposition program for extrapolation modeling," Health Physics, vol. 57, no. 1, pp. 49-59, 1989.

[32] E. R. Weibel, Morphometry of the Human Lung, Springer, Berlin, Germany, 1963. 


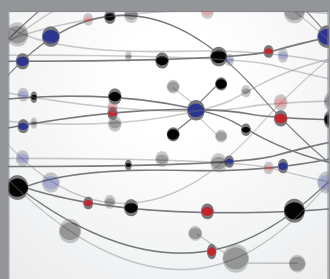

The Scientific World Journal
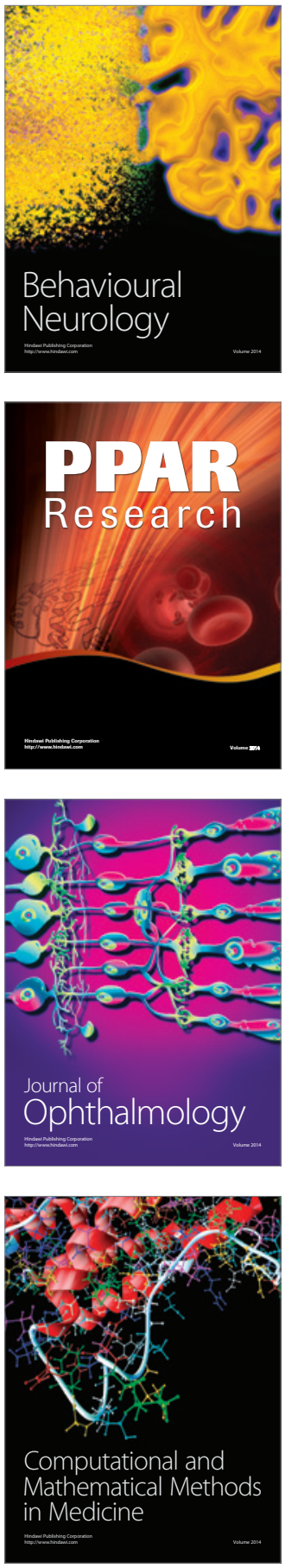

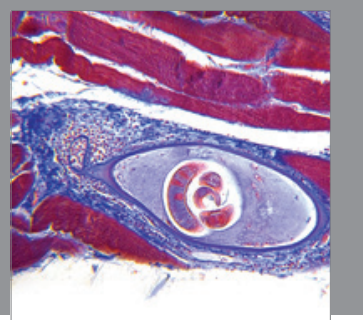

Gastroenterology

Research and Practice
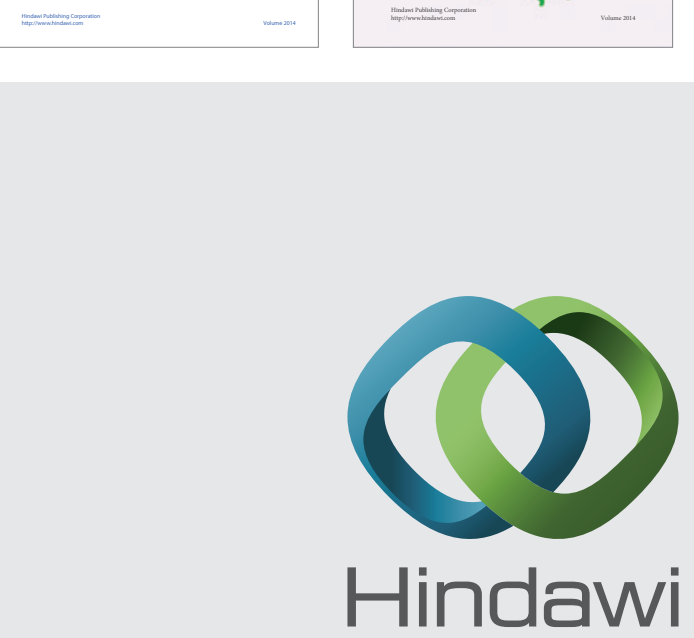

Submit your manuscripts at

http://www.hindawi.com
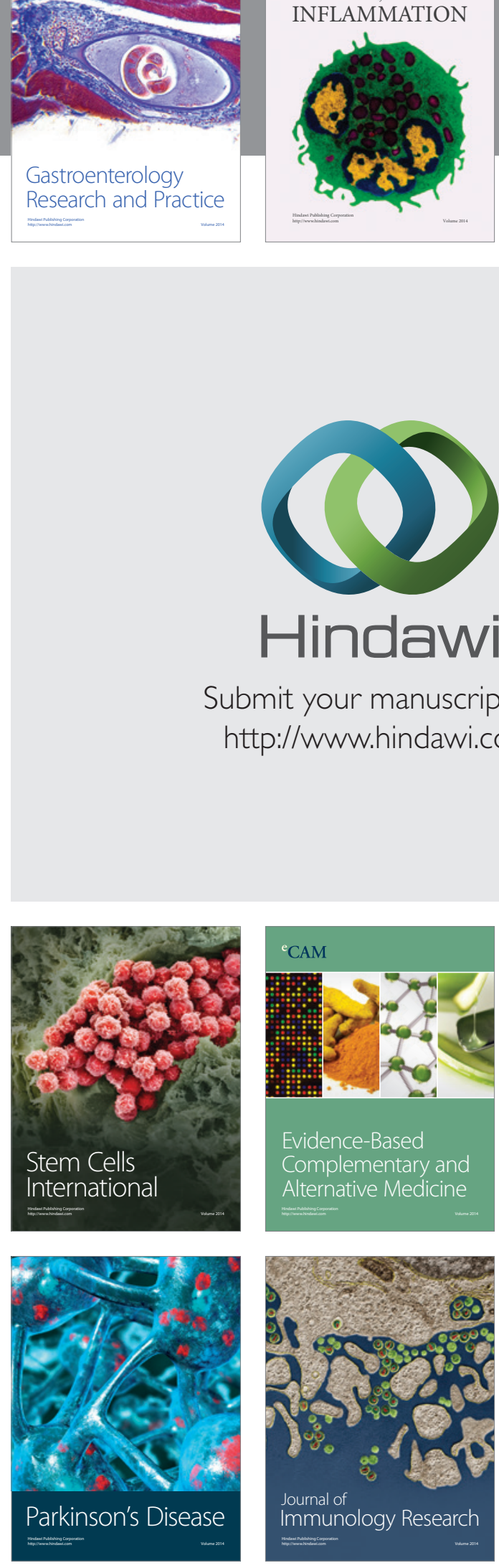

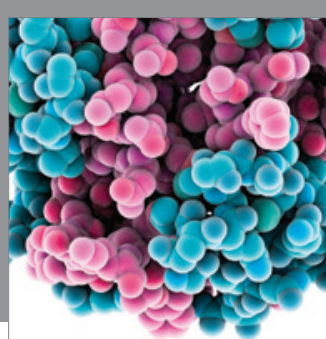

Diabetes Research
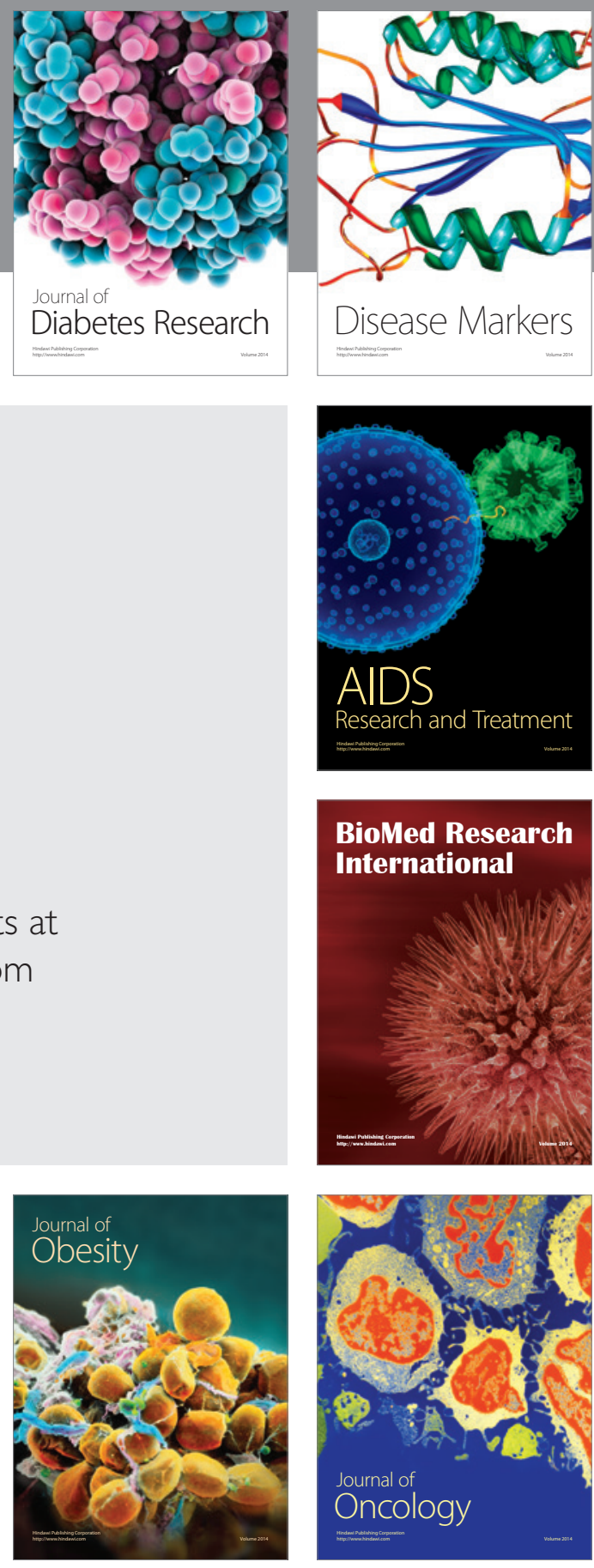

Disease Markers

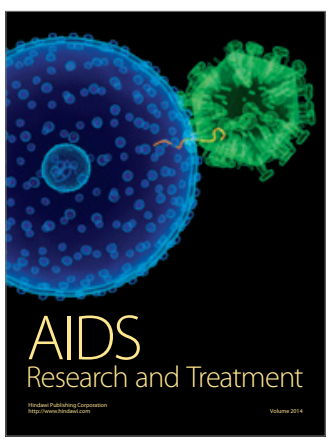

BioMed Research

International
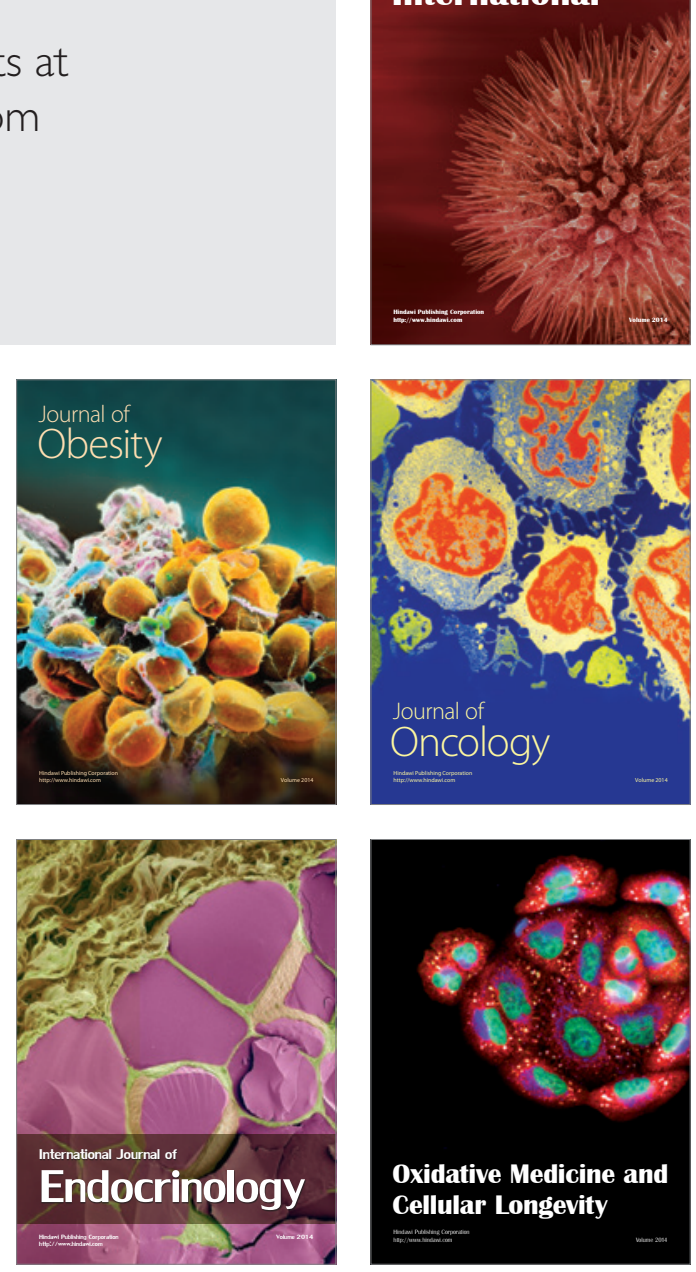